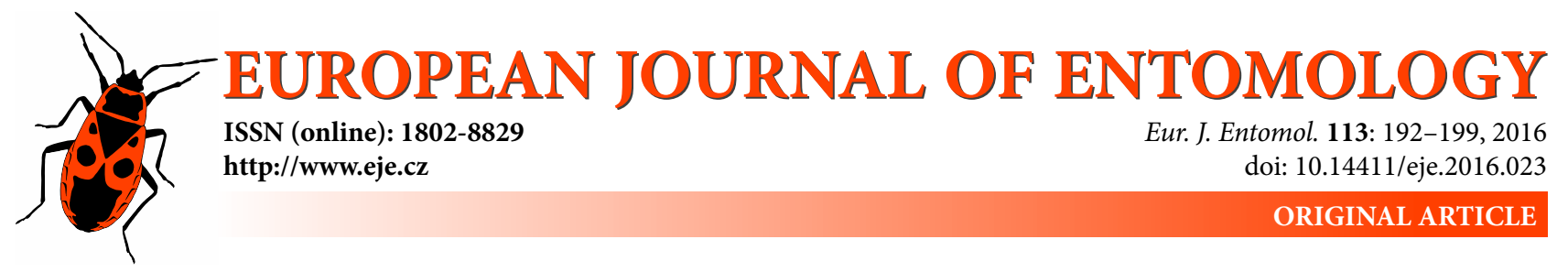

\title{
Population dynamics, seasonality and aphid prey of Cheilomenes sexmaculata (Coleoptera: Coccinellidae) in an urban park in central Japan
}

\author{
YASUKO KAWAKAMI $^{1}$, KAZUO YAMAZAKI ${ }^{2}$ and KAZUNORI OHASHI ${ }^{3}$ \\ ${ }^{1}$ Osaka Museum of Natural History, Osaka 546-0034, Japan; e-mail: yasukocafius@gmail.com \\ ${ }^{2}$ Osaka City Institute of Public Health and Environmental Sciences; e-mail: kazuo-yamazaki@city.osaka.Ig.jp \\ ${ }^{3}$ Honmachi, Toyonaka City, Osaka 560-0021, Japan; e-mail: oohasikznr@yahoo.co.jp
}

\begin{abstract}
Key words. Coleoptera, Coccinellidae, Cheilomenes sexmaculata, aphid, climate conditions, ladybird beetle, life cycle, urban vegetation
\end{abstract}

\begin{abstract}
The ladybird beetle, Cheilomenes sexmaculata (Fabricius), has been extending its distribution in and around urban areas at higher latitudes in Japan over the past 100 years. Between 2003 and 2011, we investigated the seasonal occurrence, aphid prey and population dynamics of this species in an urban park in Osaka City, central Japan. We found that $C$. sexmaculata completes three generations a year in Osaka. Overwintered adults emerge in March or April and produce two (or rarely one) generations by summer. Second-generation adults aestivate and subsequently produce another generation in autumn. This species feeds on five species of aphids that infest planted shrubs and alien weeds throughout the vegetative season. We analyzed the association between accumulated temperature and when overwintered adults first emerged. In addition, we determined the association between their time of emergence, peak abundance and last occurrence, and meteorological conditions. There was no association between the sum of effective temperatures and termination of adult overwintering. There was, however, an association between first occurrence and peak abundance, and climatic conditions, such as warm temperatures or low humidity. This species maintained a stable population in an urban park by becoming quiescent when climatic conditions were unfavourable or prey was scarce. We discussed these findings in relation to urban environmental factors, such as climate, food conditions and vegetation.
\end{abstract}

\section{INTRODUCTION}

The species diversity of some insect groups in urban areas increases while that of other insect groups decreases (Frankie \& Ehler, 1978; McIntyre, 2000; Raupp et al., 2010). Recently, it was suggested that urban areas provide footholds for the range expansion of invasive or distribution-extending insects, including ladybird beetles, (Sakuratani et al., 2000; Brown et al., 2011), buprestid beetles (Poland \& McCullough, 2006), longicorn beetles (Dodds \& Orwig, 2011), butterflies (Itô, 2001), cicadas (Takakura \& Yamazaki, 2007; Moriyama \& Numata, 2011), ants (Silverman \& Brightwell, 2008) and mosquitoes (Romi et al., 2006; Caminade et al., 2012; Li et al., 2014), worldwide. It is evident that these insects increase and extend their distributions by using the physical structures, climate and food available in urban green spaces. From the viewpoint of urban ecology and invasion biology, it is important to clarify the life cycles, population dynamics, and host use of these invasive or range-extending species of insects in urban settings in order to understand how they have adapted to the urban climate and the food available in urban space.
The ladybird beetle, Cheilomenes sexmaculata (Fabricius), is a common predator of aphids and is widely distributed across intermediate and equatorial latitudes (Sasaji, 1971). It is polymorphic in terms of its elytral colour (Kawakami et al., 2013). Over the past 100 years, C. sexmaculata has extended its distribution into higher latitudes, from Kyushu to Kanto-Hokuriku in Japan, with global warming (Kawakami et al., 2014). The northward spread of this species between 1940 and 2010 is associated with the increase in areas in Japan where the annual mean temperature is more than $15^{\circ} \mathrm{C}$ (Kawakami et al., 2014). This ladybird has been mainly collected from urban areas in Japan (858/912 individuals, $30-36^{\circ} \mathrm{N}$, Supplementary material; Kawakami et al., 2013) and is rare in suburban and mountainous areas. Despite its wide distribution, potential for regulating aphid abundance and ecological interest in its colour polymorphism and recent range extension the bionomics of $C$. sexmaculata have not been studied in detail; most studies on ladybirds are on five species and there is a need for studies on other species of ladybirds (Sloggett, 2005). 
We investigated the seasonal occurrence of $C$. sexmaculata in an urban park in Osaka City, this species was recorded between 2003 and 2011, in order to verify that it is permanently established there. In addition, to clarifying its response to fluctuations in prey abundance and seasonal changes in climate, we recorded the aphid prey available for the different generations of this ladybird based on field surveys and the association between this ladybird's activity and changes in meteorological conditions using an online database.

\section{MATERIAL AND METHODS}

\section{Seasonal occurrence of $C$. sexmaculata in Osaka City}

To investigate the seasonal occurrence of $C$. sexmaculata, we carried out field surveys five to seven times a month from 10 March 2003 to 10 December 2011. This study was carried out in Nagai Park $\left(34^{\circ} 36^{\prime} \mathrm{N}, 135^{\circ} 30^{\prime} \mathrm{E}\right.$; altitude, $10 \mathrm{~m}$; area, $\left.65.7 \mathrm{ha}\right)$, Osaka City, central Japan. Nagai Park is located in the centre of an urban area that is more than $10 \mathrm{~km}$ from the nearest suburban areas because of recent urbanization and is covered patchily with planted shrubs. We chose a 30 -ha area with many planted shrubs. The field surveys, which each lasted for 1-2 $\mathrm{h}$ between 10:00 and 13:00 on sunny or cloudy days, were carried out by the first author (YK), and the time spent surveying was recorded. Planted shrubs and weeds where the aphid prey occurred were searched and the numbers of larvae, teneral (newly eclosed and thus not fully coloured) adults and post-teneral adults of $C$. sexmaculata were recorded (Table 1). Then, the number of $C$. sexmaculata at each developmental stage recorded per 30 min of searching was calculated and the species of the aphids and their host plants were identified. We transferred all the adults to the laboratory, determined their sex on the basis of their head colour (male, pearly white; female, muddy black; Sasaji, 1977), and returned them on the same day to the plants from which they were collected.

To determine the number of generations per year for $C$. sexmaculata, the numbers of larvae, total adults (including both teneral and post-teneral), and teneral adults recorded per $30 \mathrm{~min}$ of searching were plotted on a graph, which revealed the population dynamics for each year from 10 March to 10 December 2003 2011. Deviations from a 1:1 sex ratio for each year from 2003 to 2011 was analyzed using $\chi^{2}$-tests for independence with JMP 11 Discovery (SAS Institute Inc., Cary, NC, USA).

\section{Correlation between the emergence of overwintered adults and the sum of effective temperatures}

C. sexmaculata adults that emerge in autumn overwinter and emerge the following spring in Gifu, central Japan (Hukusima \& Kouyama, 1974). The association between the first day on which freshly emerged adults were recorded and previous meteorological conditions was calculated. Generally, the first day of emer- gence of overwintered adults can be predicted using the lower developmental threshold (LDT) of the pre-oviposition period to calculate the sum of effective temperatures (SET) (Yanagi, 1980; Teixeira \& Polavarapu, 2001; Yao, 2002). Specifically, it is predicted to be the day when the cumulative difference between the daily maximum temperature (DMT) and LDT reach SET calculated from the day when DMT exceeds LDT (Yanagi, 1980; Yao, 2002).

Therefore, using LDT of the pre-oviposition period for the population from Kyoto $\left(12.7^{\circ} \mathrm{C}\right.$, Kiritani, 2012), which is the closest population to Osaka for which this information is available, we calculated the temperature that accumulated from winter up to the first day of emergence of overwintered adults. Namely, the difference in degrees centigrade between DMT and $12.7^{\circ} \mathrm{C}$ was integrated from the last day when DMT was less than $12.7^{\circ} \mathrm{C}$ to the first day of emergence over the period 2003-2011. To determine whether SET can be used to predict accurately the first day of occurrence, we compared the cumulative temperatures in each year to the SET of the pre-oviposition period for the Kyoto population (54.3 day-degrees, Kiritani, 2012). DMT of Osaka City recorded at the nearest meteorological station, $7 \mathrm{~km}$ from the study site, was obtained from an online database compiled by the Japanese Meteorological Agency (http://www.data.jma.go.jp/obd/stats/ etrn/index.php).

\section{Correlations between day of first occurrence, peak abundance and day of last occurrence, and meteorological conditions}

Seasonal activity of insects can be affected by seasonal changes in meteorological conditions, in addition to cumulative temperatures or critical photoperiods (Brittain, 1982; Fellers, 1989; Høye \& Forchhammer, 2008). Therefore, we determined the association between days of first occurrence of overwintered and aestivating adults, peak abundance of overwintered and autumn generations and last occurrence of autumn generation, and meteorological conditions. Records of mean, maximum and minimum temperatures; mean humidity; and duration of sunshine on the above mentioned five days in 2003-2011 were obtained from an online database compiled by the Japanese Meteorological Agency (http://www.data.jma.go.jp/obd/stats/etrn/index.php). Coefficients of variation $(\mathrm{CV})$ for the nine years for each of the five climatic measurements were calculated for each day. On the basis of these results, we determined the association between the phenology of this ladybird and changes in weather conditions.

\section{RESULTS}

\section{Seasonal occurrence and aphid prey of C. sexmaculata in Osaka}

The numbers of larvae, all adults and teneral adults of C. sexmaculata recorded in $30 \mathrm{~min}$ of searching from 10 March to 10 December are shown in Fig. 1 for each year

Table 1. Aphid prey of Cheilomenes sexmaculata, their host plants and the ladybird generation that fed on each aphid species in Osaka City in 2003-2011. OW - overwintered, SP - spring, SM - summer, OS - over summered and AT - autumn generations.

\begin{tabular}{|c|c|c|}
\hline Aphid & Host plant(s) of aphid & Ladybird generation \\
\hline \multirow[t]{3}{*}{ Aphis spiraecola Patch } & Vinca major L. & OW, AT \\
\hline & Abelia x grandiflora (Rovelli ex André) Rehder & $\mathrm{SP}$ \\
\hline & Chaenomeles speciosa (Sweet) Nakai & $\mathrm{SP}$ \\
\hline \multirow[t]{2}{*}{ Aphis gossypii Glover } & Rhaphiolepis indica (L.) Lindl. var. umbellata (Thunb.) H. Ohashi & SP, OS, AT \\
\hline & Hibiscus mutabilis L. & OS, AT \\
\hline Uroleucon nigrotuberculatum (Olive) & Solidago altissima L. & SM \\
\hline Aphis nerii Boyer de Fonscolombe & Nerium oleander L. var. indicum (Mill.) O. Deg. et Greenwell & SM \\
\hline Tinocallis kahawaluokalani (Kirkaldy) & Lagerstroemia indica L. & OS, AT \\
\hline
\end{tabular}



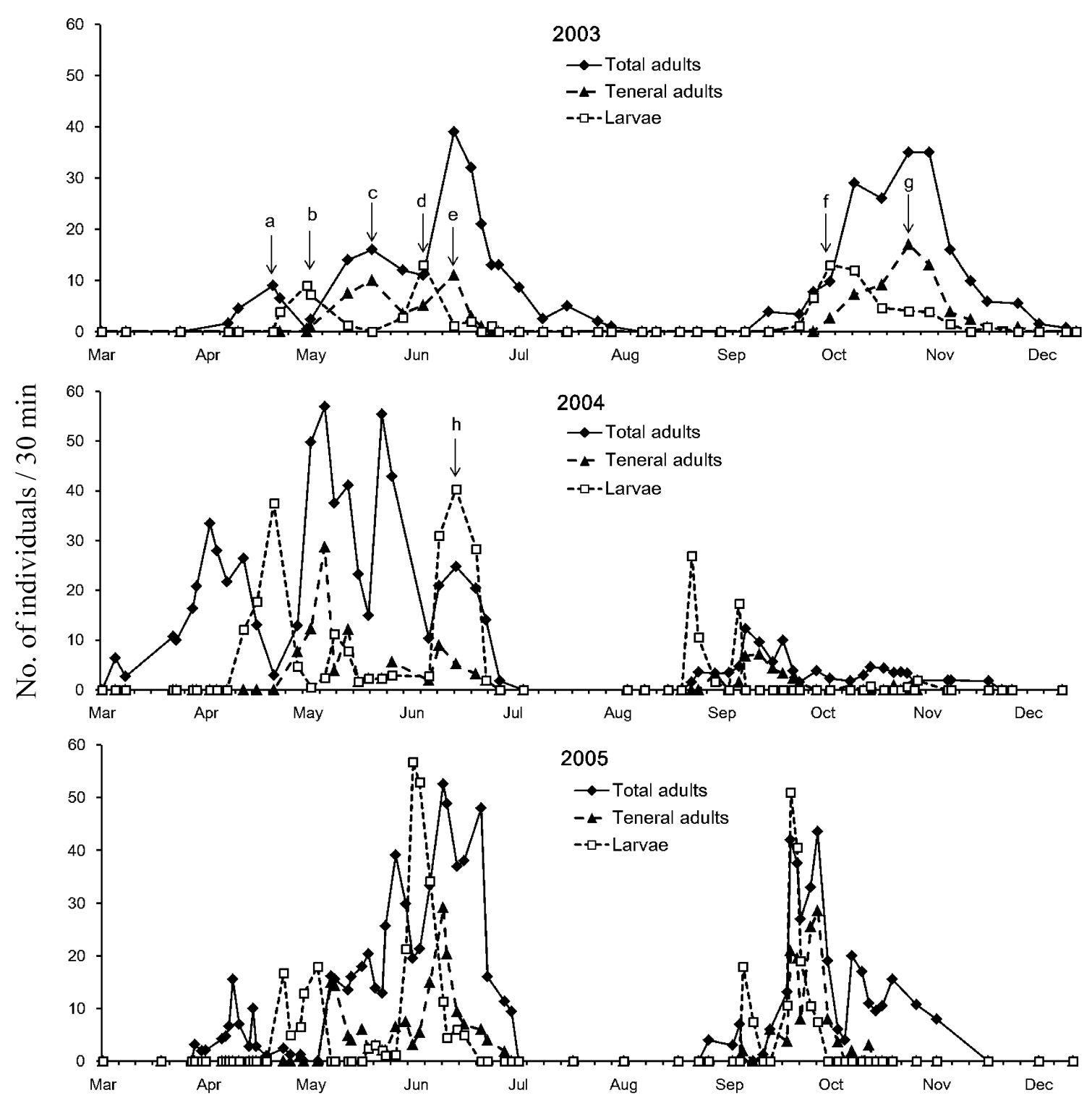

Fig. 1 (continues on following pages). Seasonal changes in the number of larvae, teneral adults and total adults of Cheilomenes sexmaculata recorded in Osaka City in 2003-2011. Significance of each arrow is explained in the text.

(2003-2011). Aphid prey and host plants of the aphids are listed in Table 1. First, we describe the seasonality of $C$. sexmaculata and its prey in 2003 , as it is representative of the entire nine-year study. Overwintered (OW) adults were first observed on 16 April in a colony of Aphis spiraecola Patch (Fig. 1). Adult numbers increased with time and were most numerous on 29 April (Fig. 1, arrow "a") and declined to their lowest level on 9 May. With the decrease in OW adults, larvae of the spring generation (SP) occurred in colonies of $A$. spiraecola and Aphis gossypii Glover. The number of larvae was the highest on 9 May (Fig. 1, arrow "b"). With the decrease in SP larvae, teneral adults of SP occurred on the same hosts with SP larvae. The number of SP teneral adults was highest on 28 May (Fig. 1, arrow "c"). On 6 June, larvae of the summer generation (SM) occurred in colonies of Uroleucon nigrotuberculatum (Olive) and Aphis nerii Boyer de Fonscolombe. SM larvae were most abundant on 12 June (Fig. 1, arrow "d"). The decrease in SM larvae and teneral adults of SM occurred on the same hosts with SM larvae. The number of SM teneral adults peaked on 21 June (Fig. 1, arrow "e").

Neither $C$. sexmaculata nor aphids were observed from 6 August until adults that had over summered (OS) were found on 21 September in colonies of Tinocallis kahawaluokalani (Kirkaldy) and A. gossypii. After the appearance of OS adults, larvae of the autumn generation (AT) occurred on the same hosts together with OS adults, and the number of larvae peaked on 9 October (Fig. 1, arrow "f'). AT teneral adults occurred on the same hosts with AT larvae. The number of AT teneral adults was highest on 1 November (Fig. 1, arrow "g"). AT adults were recorded in colonies of A. spiraecola on its host plant Vinca major L. from 22 October to 17 December. A. spiraecola was recorded intermittently on $V$. major during winter between 2003 and 2011.

With respect to the seasonal occurrences from 2004 to 2011, we have highlighted the differences from those recorded in 2003. In 2005, 2007 and 2008, C. sexmaculata 

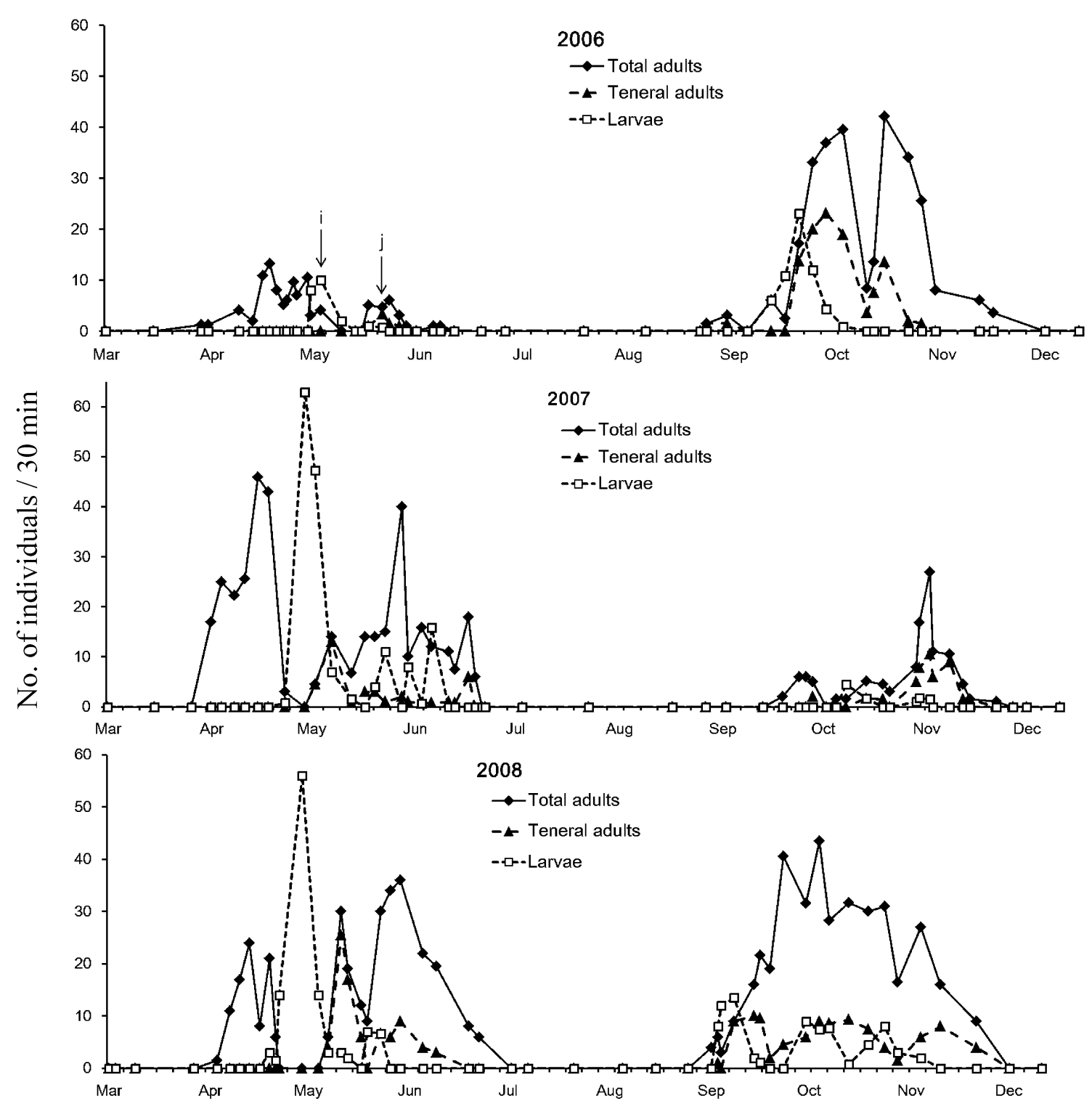

Fig. 1 (continued).

completed three generations per year, i.e. SP, SM and AT generations (Fig. 1). However, there were differences in the days of first occurrence, peak timing and last occurrence of adults and larvae and the patterns in their population dynamics (Fig. 1). In 2004 and 2009, the peak number of third generation larvae occurred in summer (Fig. 1; 2004, arrow "h"; 2009, arrow "k"); however, no adults of this generation were recorded (Fig. 1). In 2006 and 2011, only one generation, i.e. the peak of SP larvae and adults, was recorded from spring to summer (Fig. 1; 2006, arrows "i" and "j"; 2011, arrows "m" and "n"). In 2010, despite SM larvae occurring on 14 June (Fig. 1, arrow "l”), no SM teneral adults were recorded (Fig. 1). During midsummer in 2004 to 2011, this species was not recorded, as in 2003. Moreover, OS adults occurred in late summer, and, subsequently, one generation, i.e. AM larvae and adults, was recorded in autumn despite the annual variation in population size.

Between 2003 and 2011, the first OW adults was recorded in A. spiraecola colonies on Vinca major, where the last
AT adults were found the previous year. Prey aphids and their host plant were similar over the period 2003 and 2011. Sex ratio (male/female) varied from 0.7070 to 0.9402 in 2003-2011 (Table 2) and was significantly female-biased in 2003, 2006, 2008 and 2010 ( $p$ value, 0.3528 to $<0.0001$; df $=1$; Table 2).

Table 2. Sex ratio (male/female) and $x^{2}$-tests of the independence of adult numbers $(p)$ of both sexes of Cheilomenes sexmaculata in Osaka City in 2003-2011. df = 1 .

\begin{tabular}{cccrc}
\hline Year & Sex ratio & $X^{2}$ value & $p$ value & No. of individuals \\
\hline 2003 & 0.7732 & 16.88 & $<0.0001$ & 1032 \\
2004 & 0.9203 & 1.370 & 0.2418 & 795 \\
2005 & 0.9402 & 0.863 & 0.3528 & 908 \\
2006 & 0.6621 & 15.04 & 0.0001 & 364 \\
2007 & 0.8120 & 4.876 & 0.0272 & 453 \\
2008 & 0.7070 & 17.85 & $<0.0001$ & 606 \\
2009 & 0.8750 & 1.533 & 0.2156 & 345 \\
2010 & 0.7917 & 6.977 & 0.0083 & 516 \\
2011 & 0.8092 & 2.637 & 0.1044 & 237 \\
\hline
\end{tabular}




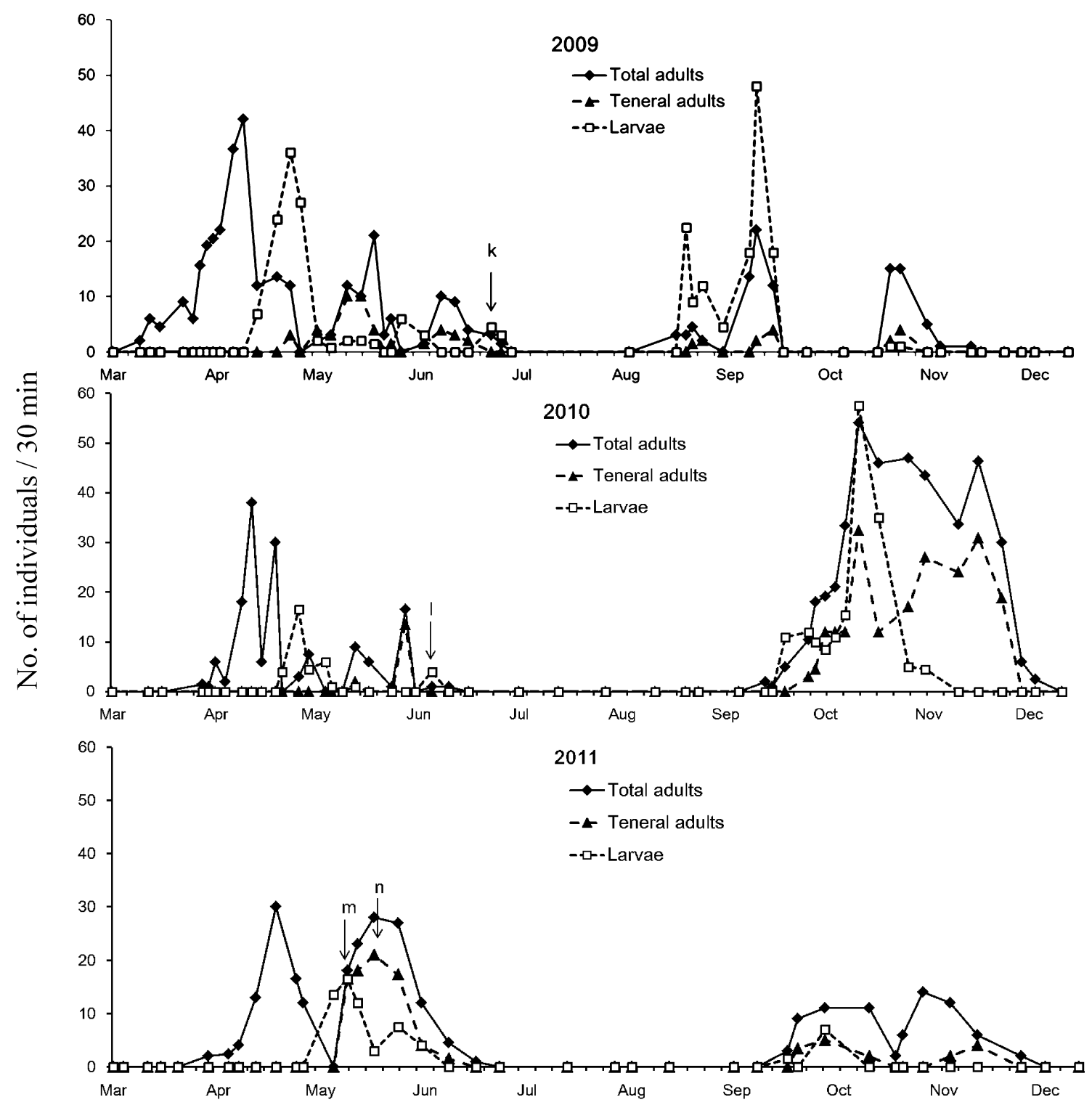

Fig. 1 (continued).

\section{Adult activity and weather conditions}

Sum of effective temperatures (SET) from winter to the first day of occurrence of OW adults in 2003-2011 are listed in Table 3. SET varied from 47.3 to 166.6 (Table 3).

Table 3. Sum of effective temperatures recorded over the period from the last day when the daily maximum temperature was less than $12.7^{\circ} \mathrm{C}$ to the first day of occurrence of overwintered adult Cheilomenes sexmaculata in Osaka City in 2003-2011.

\begin{tabular}{ccc}
\hline Year & Integrated period & $\begin{array}{c}\text { Sum of effective } \\
\text { temperatures }\end{array}$ \\
\hline 2003 & Feb. 7-Apr. 15 & 124.3 \\
2004 & Feb. 13-Mar. 13 & 56.9 \\
2005 & Feb. 23-Apr. 5 & 83.2 \\
2006 & Feb. 14-Apr. 6 & 81.0 \\
2007 & Feb. 5-Apr. 9 & 166.6 \\
2008 & Feb. 22-Apr. 11 & 155.7 \\
2009 & Feb. 12-Mar. 17 & 47.3 \\
2010 & Feb. 9-Apr. 5 & 138.7 \\
2011 & Feb. 4-Apr. 6 & 94.8 \\
\hline
\end{tabular}

$\mathrm{CV}$ values for the five weather parameters, i.e. mean, maximum and minimum temperatures; mean humidity; duration of sunshine on each day [first occurrence (OW and OS adults), peak abundance (OW and AT adults), and last occurrence (AT adults)] for the nine years are presented in Table 4. CV values for two combinations were lower than 0.1 (Table 4): the first day of occurrence of OW adults and the maximum temperature (Table $4,0.0896$ ) and the day of peak abundance of AT adults and mean humidity (Table 4, 0.0856).

\section{DISCUSSION}

Annual and seasonal occurrence of $C$. sexmaculata and availability of its aphid prey in an urban environment

On the basis of a long-term field census (2003-2011) of the seasonal occurrence of $C$. sexmaculata in Osaka City this species usually completes three generations a year: SP, SM and AT generations (Fig. 1). However, the seasonality 
Table 4. Relationship between the phenology of Cheilomenes sexmaculata in Osaka City and meteorological parameters measured by coefficients of variation (CV) recorded from 2003 to 2011.

\begin{tabular}{|c|c|c|c|c|c|}
\hline Factor & Mean temp. & Max. temp. & Min. temp. & Mean humidity & Sunshine duration \\
\hline First day of occurrence of OW & 0.1246 & 0.0896 & 0.2391 & 0.1204 & 0.1220 \\
\hline Peak day of occurrence of OW & 0.1884 & 0.1448 & 0.2819 & 0.1558 & 0.3968 \\
\hline First day of occurrence of OS & 0.1088 & 0.1100 & 0.1412 & 0.1079 & 0.4130 \\
\hline Peak day of occurrence of AT & 0.1333 & 0.1372 & 0.1790 & 0.0856 & 0.4039 \\
\hline Last day of occurrence of AT & 0.1927 & 0.1615 & 0.3021 & 0.1190 & 0.4598 \\
\hline
\end{tabular}

and number of generations does vary from year to year; for example, the peak of third-generation larvae occurred in summer in some years (2004 and 2009), while in other years, only one generation was recorded in summer (2006, 2010, and 2011). This variation in seasonal occurrence may be caused by variation in climatic conditions and/or in the abundance of aphids from year to year, although immigration from and emigration to outside the study area cannot be completely ruled out as a causative factor for this annual variation in phenology. Abundance and species composition of the aphid prey, host plants, microclimate and the surrounding landscape are important as determinants of the presence or absence of coccinellid species at a particular site (Honěk, 2012). Among these factors, prey availability is likely to be the primary factor determining the activity and reproduction, as reported by Honěk (2012) for other predacious ladybirds, which like C. sexmaculata are dependent on aphids that are an ephemeral resource.

Neither aphids nor adult $C$. sexmaculata were recorded in summer between 2003 and 2011 in Osaka (Fig. 1). Therefore, it is likely that adults were inactive then due to the lack of prey. In fact, females from a Gifu population of this species continued to oviposit during summer when they were continuously fed aphids (Hukusima \& Kouyama, 1974). This indicates that the summer quiescence of adults is caused by the lack of prey. It is well known that the number of aphids decreases in summer because of high temperatures, maturity of host plants and increased parasitoid activity (Dixon, 1977; Karley et al., 2003). Warming due to the urban heat island effect in summer may also further reduce the abundance of prey.

Sex ratio was female-biased in four of the years between 2003 and 2011 in Osaka (Table 2). The basic sex ratio in coccinellids is close to 50:50, except when they are infected with a male-killing agent (Nedvěd \& Honěk, 2012). Since females need to bask in order to increase their body temperature for egg production, they are easy to find on plant leaves; this could be a possible reason for the bias.

C. sexmaculata extended its distribution in Japan from Kyushu $\left(33^{\circ} \mathrm{N}\right)$ to Kanto-Hokuriku $\left(36^{\circ} \mathrm{N}\right)$ between 1930 and 1990, but this spread northwards ceased after the 1990s (Kawakami et al., 2014). This study indicates that, since the spread north ceased, the Osaka population $\left(35^{\circ} \mathrm{N}\right)$ has continuously persisted there. The conditions in urban parks in Osaka, i.e. the urban climate and/or prey availability, may be suitable for this ladybird beetle. In fact, aphids are more abundant in urban parks because of the cultivation there of their host plants (Table 1), which are watered and sprout again after pruning (Frankie \& Ehler, 1978; Raupp et al., 2010).

\section{Onset of adult activity and potential mechanisms}

Sum of effective temperatures from winter up to the first day of occurrence of OW adults were higher than the SET of Kyoto populations (54.3) in 2003-2011, except in 2009 (47.3) (Table 3). Even when SETs were exceeded, spring activity did not start. The small CV value indicates that the first day of occurrence of OW adults is related to the daily maximum temperature (Table 4), thus, OW adults may resume activity on days when temperatures are favourable. Alternatively, OW adults may bask and/or feed on warm days after physiologically emerging from overwintering due to accumulating the required SET. An increase in photoperiod and habitat disturbance is required to break the diapause of ladybirds, in addition to increasing temperatures (Hodek et al., 1977). C. sexmaculata in Nagai Park seem to overwinter in hibernacula close to $V$. major, since OW adults and the last AT adults were recorded in A. spiraecola colonies infesting $V$. major. Since $A$. spiraecola occurred throughout winter, it is unlikely that the first day of occurrence of OW adults is associated with the availability of this aphid. The Palearctic ladybird species Coccinella septempunctata L., which is adapted to cold conditions, produces one generation in central Japan in winter in artificial thermal microhabitats in which aphids occur during winter (Ohashi et al., 2005). Nevertheless, C. sexmaculata, which originated from tropical and subtropical regions, did not reproduce in winter in Osaka.

In contrast to the beginning of $\mathrm{OW}$ adult activity, the first day of occurrence of OS adults may not be related to any meteorological condition. Since OS adults were recorded at the same time as the occurrence of aphids on three host plants (Table 1), the timing of their activity after aestivation may be associated with prey availability. The time of the peak abundance of AT adults may be related to mean humidity (Table 4); AT adults are thus likely to become active when the level of humidity is favourable. As stated above, it is presumed that the beginning of and peak activity of $C$. sexmaculata adults depends on favourable weather or prey availability.

Harmonia axyridis (Pallas) is known to complete two generations a year on Honshu, the main island of Japan, and overwintering females are in reproductive diapause, whereas, aestivating females are in dormancy (Sakurai et al., 1988). Currently, the diapause status of $C$. sexmaculata has not been elucidated for either overwintering or aestivation. In this study, AT larvae and OS adults occurred at al- 
most the same time, but SP larvae occurred later than $\mathrm{OW}$ adults (Fig. 1). This indicates that OW females could not oviposit immediately after overwintering, since a definite period may be necessary for ovarian development. Therefore, the C. sexmaculata that overwinter in Osaka may be in diapause and those that aestivate are dormant.

In conclusion, this field survey clearly indicates that the Osaka population of $C$. sexmaculata can persist there because of the favourable biotic and abiotic environment that exist in urban green areas. Since this species has extended its distribution recently and was mainly collected from urban areas, urban vegetation may have enabled this distributional expansion. Vegetation moderates urban climatic extremes by absorbing solar radiation and via evapotranspiration, and various insects, including ladybird beetles, and their aphid and scale prey use urban vegetation as habitats (Frankie \& Ehler, 1978; McIntyre, 2000; Raupp et al., 2010). Therefore, for C. sexmaculata in Japan, use of urban vegetation appears to be a crucial factor enabling it to become established and extend its range. To test this hypothesis, comparative studies of population censuses of aphid prey in urban, suburban and rural areas are required, which would elucidate the differences in seasonality, survival and population trends in these habitats. Because it is difficult to study rural habitats because of the very low population density of $C$. sexmaculata, the introduction of egg batches into rural areas and subsequent monitoring may be promising way of studying this species in this habitat.

ACKNOWLEDGEMENTS. We are grateful to N. Osawa (Kyoto University), M. Yokogawa (Osaka Museum of Natural History), J. Sloggett (Maastricht University) and two anonymous reviewers for their helpful suggestions. We would like to express our special gratitude to M. Okamoto (Osaka Museum of Natural History) for his assistance with the survey.

\section{REFERENCES}

Brittain J.E. 1982: Biology of mayflies. - Annu. Rev. Entomol. 27: 119-147.

Brown P.M.J., Thomas C.E., Lombaert E., JefFries D.L., Estoup A. \& Handeey L.-J.L. 2011: The global spread of Harmonia axyridis (Coleoptera: Coccinellidae): distribution, dispersal and routes of invasion. - BioControl 56: 623-641.

Caminade C., Medlock J.M., Ducheyne E., McIntyre K.M., Leach S., Baylis M. \& Morse A.P. 2012: Suitability of European climate for the Asian tiger mosquito Aedes albopictus: recent trends and future scenarios. - J. R. Soc. Interface 9: $2708-2717$.

Dixon A.F.G. 1977: Aphid ecology: life cycles, polymorphism, and population regulation. - Annu. Rev. Ecol. Syst. 8: 329 353.

Dodds K.J. \& Orwig D.A. 2011: An invasive urban forest pest invades natural environments - Asian longhorned beetle in northeastern US hardwood forests. - Can. J. For. Res. 41: 1729-1742.

FelLers J.H. 1989: Daily and seasonal activity in woodland ants. -Oecologia 78: 69-76.

FrankiE G.W. \& EhLer L.E. 1978: Ecology of insects in urban environments. - Annu. Rev. Entomol. 23: 367-387.

Hodek I., Iperti G. \& Rolley F. 1977: Activation of hibernating Coccinella septempunctata (Coleoptera) and Perilitus coc- cinellae (Hymenoptera) and the photoperiodic response after diapause. - Entomol. Exp. Appl. 21: 275-286.

HoNĚK A. 2012: Distribution and habitats. In Hodek I., van Emden H. F. \& Honěk A. (eds): Ecology and Behaviour of the Ladybird Beetles (Coccinellidae). Wiley-Blackwell, Oxford, pp. $110-140$.

Høye T.T. \& ForchHammer M.C. 2008: The influence of weather conditions on the activity of high-arctic arthropods inferred from long-term observations. - BMC Ecology 8: 8, 7 pp.

Hukusima S. \& Kouyama S. 1974: Life histories and food habits of Menochilus sexmaculatus Fabricius (Coleoptera: Coccinellidae). - Res. Bull. Fac. Agric. Gifu Univ. 36: 19-29.

ITô Y. 2001: Ecology of a subtropical fritillary, Argyreus hyperbi$u s$, in an urban area near Nagoya City, Honshu, Japan. - Jpn. J. Entomol. (N. S.) 4: 73-79 [in Japanese].

Karley A.J., Pitchford J.W., Douglas A.E., Parker W.E. \& HowARD J.J. 2003: The causes and processes of the mid-summer population crash of the potato aphids Macrosiphum euphorbiae and Myzus persicae (Hemiptera: Aphididae). — Bull. Entomol. Res. 93: 425-438.

KawaKami Y., Yamazaki K. \& Ohashi K. 2013: Geographical variations of elytral color polymorphism in Cheilomenes sexmaculata (Fabricius) (Coleoptera: Coccinellidae). - Entomol. Sci. 16: 235-242.

KaWaKami Y., Yamazaki K. \& Ohashi K. 2014: Northward expansion and climatic factors affecting the distribution limits of Cheilomenes sexmaculata (Coleoptera: Coccinellidae) in Japan. - Appl. Entomol. Zool. 49: 59-66.

KIRITANI K. 2012: The low development threshold temperature and the thermal constant in insects and mites in Japan (2nd edition). - Bull. Natl. Inst. Agro-Environ. Sci. 31: 1-74 [in Japanese].

Li Y., Kamara F., Zhou G., Puthiyakunnon S., Li C., Liu Y., Zhou Y., YAO L., YAN G. \& ChEN X.G. 2014: Urbanization increases Aedes albopictus larval habitats and accelerates mosquito development and survivorship. - PLoS Negl. Trop. Dis. 8(11): e3301, 12 pp.

MCINTYRE N.E. 2000: Ecology of urban arthropods: a review and a call to action. - Ann. Entomol. Soc. Am. 93: 825-835.

Moriyama M. \& Numata H. 2011: A cicada that ensures its fitness during climate warming by synchronizing its hatching time with the rainy season. - Zool. Sci. 28: 875-881.

NEDVĚD O. \& HoNĚK A. 2012: Life history and development. In Hodek I., van Emden H.F. \& Honěk A. (eds): Ecology and Behaviour of the Ladybird Beetles (Coccinellidae). Wiley-Blackwell, Oxford, pp. 54-109.

Ohashi K., Sakuratani Y., Osawa N., Yano S. \& Takafuji A. 2005: Thermal microhabitat use by the ladybird beetle, Coccinella septempunctata (Coleoptera: Coccinellidae), and its life cycle consequences. - Environ. Entomol. 34: 432-439.

Poland T.M. \& MuCullough D.G. 2006: Emerald ash borer: invasion of the urban forest and the threat to North America's ash resource. - J. Forestry 104: 118-124.

Raupp M.J., Shrewsbury P.M. \& Herms D.A. 2010: Ecology of herbivorous arthropods in urban landscapes. - Annu. Rev. Entomol. 55: 19-38.

Romi R., SEVErinI F. \& Toma L. 2006: Cold acclimation and overwintering of female Aedes albopictus in Roma. - J. Am. Mos. Contr. Assoc. 22: 149-151.

SAKURAI H., TAKedA S. \& KaWAi T. 1988: Diapause regulation in the lady beetle, Harmonia axyridis. In Niemczyk E. \& Dixon A.G.F. (eds): Ecology and Effectiveness of Aphidophaga. SPS Acad. Publ., The Hague, pp. 67-70.

Sakuratani Y., Matsumoto Y., Oka M., Kubo T., Fuji A., Uotani M. \& Teraguchi T. 2000: Life history of Adalia bipunctata 
(Coleoptera: Coccinellidae) in Japan. — Eur. J. Entomol. 97: $555-558$.

SASAJI H. 1971: Genus Menochilus Timberlake. In Sasaji H. (ed.) Fauna Japonica Coccinellidae (Insecta: Coleoptera). Acad. Press of Japan, Tokyo, pp. 284-286.

SASAJI H. 1977: Distinction of the sex (Coccinellidae). - The Insectarium 14: 269 [in Japanese].

Silverman J. \& Brightwell R.J. 2008: The Argentine ant: challenges in managing an invasive unicolonial pest. - Annu. Rev. Entomol. 53: 231-252.

Sloggett J.J. 2005: Are we studying too few taxa? Insights from aphidophagous ladybird beetles (Coleoptera: Coccinellidae). — Eur. J. Entomol. 102: 391-398.

TAKAKURA K.-I. \& YAMAZAKI K. 2007: Cover dependence of predation avoidance alters the effect of habitat fragmentation on two cicadas (Hemiptera: Cicadidae). - Ann. Entomol. Soc. Am. 100: 729-735.
Teixeira L.A.F. \& Polavarapu S. 2001: Postdiapause development and prediction of emergence of female blueberry maggot (Diptera: Tephritidae). - Environ. Entomol. 30: 925-931.

YANAGI T. 1980: Study on differentiation and dormancy in ecotype of Eysarcoris aeneus (Scopoli). - Nagano Nosoushiho 6: 42-55 [in Japanese].

YAO M. 2002: Development number of annual generations and the relationship of effective heat unit and to abundance of over-wintered adults in the following year of the white-spotted spined bug, Eysarcoris aeneus (Scopoli) (Heteroptera: Pentatomidae). - Jpn. J. Appl. Entomol. Zool. 46: 15-21 [in Japanese].

Received April 20, 2015; revised and accepted January 20, 2016 Published online February 5, 2016 